\title{
Musician-Teacher collaborations in composing contemporary music in secondary schools
}

\author{
Victoria Kinsella, Birmingham City University \\ Martin Fautley, Birmingham City University \\ Nancy Evans, Birmingham Contemporary Music Group
}

\section{Introduction}

This chapter describes the Resolution composing project, a partnership between Birmingham Contemporary Music Group and the Rheumatology Research Group based at the Institute of Biomedical Research at the University of Birmingham, along with researchers from Birmingham City University. This composing project involved pupils aged 14 and 15 years old from three local secondary schools creating their own compositions from a specific set of stimuli. It was funded by The Wellcome Trust, involved biomedical scientists and composers working with classroom music teachers and young people to create new music around the theme of auto-immune disease. The title, 'Resolution', comes from a terminology connected with rheumatoid arthritis, and, of course, music.

\section{The English context}

In order to understand the collaborations described in this chapter, we begin with a description of music in the English National Curriculum (NC). At the time of this research, music was a statutory subject for all pupils up to the age of 14 years. The $\mathrm{NC}$ itself can be considered as generalist music education. It involves three main activities: Composing, Performing, and Listening. This makes it different from music education in some other jurisdictions, in that it does not employ a primarily ensembleperformance based modality. Instead, what takes place is that pupils learn to perform using classroom instruments, such as tuned and unturned percussion, guitars, keyboards, and music technology. Pupils that play instruments other than these often bring them into the class too. Composing normally takes place directly into sound, it does not need to involve stave notation, although it can. The Resolution project was 
designed to help the participating schools with the composing aspect of their National Curriculum work. It is important to note that pedagogies for composing are sometimes considered an area that teachers struggle with (Berkley 2001, Fautley 2014, Kenny 2014).

\section{Historical Background - Composers working in schools in England}

Since the early 1980s, professional composers and orchestral musicians have worked in schools delivering composition projects as part of orchestral education programs. In England, the London Sinfonietta was one of the first orchestras to employ an Education Officer, Gillian Moore, in 1983. Their very first project involved composer George Benjamin and former LPO flautist Richard McNicol working with twenty teachers from ILEA. The focus of the project was to prepare a group of children and their teachers for attendance at a concert of music by Ravel and Varese, and involved the young people creating their own Varese pastiche compositions (Ruffer 1988). This type of repertoire project, with the aim to prepare children for listening to the featured music in an upcoming concert has been the backbone of orchestral education programs for many years, and, concomitantly, of composers working in schools. More recent developments in orchestral repertoire projects tend to have a wider reach than 'bums on seats' and 'audiences of the future' projects of the past, and orchestras now employ composers to work in schools on a wide range of composition projects.

\section{The Resolution composing project}

Birmingham Contemporary Music Group (BCMG), the musical organization at the heart of this project, specializes in contemporary classical music and offers a broad range of composing projects as well as repertoire-based projects. These focus on offering young people the techniques of featured composers and their works (where applicable) and more general composing strategies to support their development as composers.

The participants were: young people aged 14-16, teachers of the young people, experienced professional composers, what were termed 'emerging' professional composers (Sawyer 2003b), and PhD-level graduate student scientists. Three 
secondary schools in Birmingham, UK, were participants, differing in type, size, cohort, cultural background, and socio-economic status. There was a comprehensive single-sex girls school, a selective academy single-sex girls school and a comprehensive academy mixed school.

The aim of the project was to generate greater understanding around inflammation, an important area of biomedical science, and to explore differences and commonalities of artistic and scientific practices. The intention was to compose, create, and perform new music based on the medical theme of inflammation. All music by both emerging composers and the young people involved was presented in a public performance at the CBSO Centre in Birmingham, a major performance venue in the heart of England's second city. It is important to note that the project was not primarily performance led, however, but the final performance did offer the young people and the composers an opportunity to demonstrate and celebrate music-making and learning in front of a wider audience. It was important for this work that the performance was carefully planned in the overall structure of the project, so that it did not take precedence over composing pedagogy and creative composing processes. It was not until the final stages of the project that the performance was made a feature of activity. It was seen therefore as a celebration of collaboration and process, rather than solely of final outcome. This runs counter to the ideology sometimes espoused in collaborative projects which can be of the 'let's put on a show' variety. In this work, it was the processes of composing, and researching these processes, which was deemed to be the most important. This accords with Sawyer's (2003a) description,

... [a] shift in creativity research from a focus on creative products to a focus on the creative process that generates them...in group creativity, the process is the essence of the genre, and it must be the central focus of any scientific study (Sawyer 2003a, 6).

\section{Project activity}

In-school activity stages of Resolution took the form of a series of workshops, in which the focus shifted as the phases of the composing developed: 
Initial phase: One workshop in which music was used to present the scientific aspects of the project.

Clarification phase: Two workshops aimed primarily at the composing work undertaken by the emerging composers, where most of the activity involved rehearsal, and getting feedback on new works they had composed for participants.

Main Workshop phase: This consisted of eight workshops in each school. This is clearly where the bulk of the composing work for the pupils took place. In these workshops the young people worked with the scientists, before composing music for an ensemble of themselves and a BCMG professional musician. To achieve this, the young people used identified scientific content as stimuli for their composing. Workshops were part-led by the established composers and part-led by the emerging composers.

What made this project differ from some other artist-in-schools work was that two additional forms of activity were scheduled from the outset. These were (i) structured reflection sessions for all the adults involved in the project, and (ii) continuing professional development CPD sessions for emerging composers.

Reflection Phase: One issue identified at the outset was that of planning. We know, often anecdotally, that some projects in school are not as effective as they might otherwise be due to a mismatch between the wants of the artist and the needs of the school (Christophersen 2015, Fautley 2014). In order to address this, three formal planning and reflection sessions took place throughout the year, alongside informal ones at the end of workshops in schools. Then, at the end of the project was a final reflection session for all the participating adults.

Continuing Professional Development (CPD) phase: Alongside the reflection phase, there were also eight CPD sessions provided for participating emerging composers. These covered a range of aspects important for those working with young people in schools, including planning for composing with young people, the national curriculum, and introductions to classroom practice and pedagogic strategies.

Reflection session: The final performance was followed by a public discussion and Q\&A session exploring commonalities and differences of artistic and scientific 
practices. Discussion provided valuable insights into actions and intentions of the partners, impact of the project, and ways in which these collaborations could continue in the future.

\section{Roles and responsibilities}

Conceptualizations of collaborative learning are often predicated on the social construction of knowledge (Lave and Wenger 1991, Wenger 1998), and notions of distributed cognition (Salomon 1993, Nardi 1996). In the case of Resolution, it was taken for granted that all pupils could work collaboratively on a composing task, this was not for the special few, but for all young people in regular classes.

An issue raised by this project was professional knowledge. Shulman (1986) describes two types of knowledge that are relevant here, content knowledge, knowledge about the subject domain and its contents; and Pedagogical Content Knowledge (PCK), knowledge concerning ways in which the subject is taught:

...the most useful forms of representation of those ideas, the most powerful analogies, illustrations, examples, explanations, and demonstrations - in a word, the ways of representing and formulating the subject that make it comprehensible to others (Shulman 1986, 6).

Professional knowledge is not, however, a unified construct. Eraut (1994), for example, describes a range of dichotomies:

...theory and practice, public knowledge and personal knowledge, propositional knowledge and process knowledge, analytic and intuitive thinking (Eraut 1994, 19)

All of these found their outworking at some point during the Resolution project. In order to investigate this more closely, we turn to describing roles played by the key stakeholders.

\section{The Composers}


The composers working on Resolution fell into two distinct categories. Established composers had experience of working with pupils in a range of schools, building relationships with teachers, and enabling project delivery. Their role in the project was to support pupils through a series of workshops, developing compositions on the scientific theme. This included demonstrating and modeling how scientific starting points could be used to generate, develop, and structure musical material. The composers also mentored emerging composers in the development of their compositions for the class.

\section{The Emerging Composers}

The emerging composers role was twofold: firstly, to compose a new piece of music for the class to perform, and, secondly, to support the composer in delivering workshops. They were asked not just to produce a new composition working alone, but to involve pupils in the composing process, for example by trying out ideas and getting feedback. A key aspect of the project was for the emerging composers to compose their own piece so that the pupils could observe a parallel model of how they might go about composing from an extra-musical starting point.

A priority for the emerging composers' professional development was to foster an understanding of classroom composing. They were offered opportunities to observe teaching and learning led by composers and teachers, and to look at interactions with pupils. There were also opportunities to develop knowledge of content, pedagogy and curriculum. It is noteworthy that emerging composers were not just seen as 'apprentices', but as composers with significant knowledge. Their specialized understanding of composing processes was drawn on by all participants. Knowledge transfer was not one way, but remained fluid between all the collaborators.

\section{The Teacher}

Resolution required teachers and composers to align composing with teaching and learning in a number of meaningful ways. For example, the composers had little personal experience of having to work with examination specifications and systems. Doing this required an integration of curriculum, as seen from the teacher's perspective, with the composer's practice. The teachers played a central role in 
aligning composer knowledge with exam specifications, and it is important not to downplay this centrality (Kenny 2010, Christophersen 2013).

For teachers, linking developing composerly thinking in their learners with increased student understanding was important. The teacher has ultimate responsibility for providing evidence of student learning, and for maintaining academic progress of the pupils. Therefore the composer's knowledge and skills had to work with, and be developed alongside, exam specifications and outcomes. Sharing responsibility through co-created sessions was important. In this project the teachers supported composers to evaluate teaching and learning, to better help pupils and ultimately reach outcomes required for examination. Likewise, the teachers were also offered the opportunity to expand their practice through observing the composers.

We know from the work of Ball (2003) that the performativity agenda currently rife in schools in England and elsewhere creates pressures on teachers to conform. This emphasis on accountability and performativity has had an impact on pedagogies of creativity in schools, especially at GCSE (inter alia Fautley et al 2011). Therefore, working with the composers opened up possibilities, encouraged new approaches and outlooks on composing for the teachers concerned.

\section{Learning and doing}

One aspect of professional knowledge which was important in Resolution was with regard to the provision of intended learning statements, a common requirement for English schools, where the teacher has to inform the class at the outset of a lesson what they will be learning. The composers were not always able to clearly articulate the intended learning that the pupils would be undertaking. This is not so much an issue of competence, but of practice and awareness. The teachers, all of whom are music graduates, were well used to doing this from the strictures of their daily lives. The importance of PCK has already been noted, and it became clear during the course of Resolution that this distinguished teachers from composers. As Bowman observes: 
.... a music education professional ... is not simply a musician with pedagogical training. Music education professionals are not mere music specialists (musicians) who happen to teach (Bowman 2007, 114)

This is an important conceptualization. At some point in their education teachers and composers would have rubbed shoulders, in the University, or in the Conservatoire; it is what happened next, and their professional induction into their various communities of practice (Lave and Wenger 1991, Kenny 2016) that makes a difference to their respective professional knowledge. This is not to say that composers lacked aspects of PCK, far from it, but having to deal with it did not form part of their everyday work. By way of exemplification, for composers, meaning often emerges from a process of doing, and then learning follows. For schools, this is not the way learning is conceptualized. At the beginning of the project, the notion of pre-specifying learning was resisted by some of the composers, "I don't know in advance what they are going to learn", one said. However, once exploration of this had taken place in reflection sessions this often turned out not to be the case. The composers did know, but they were unused to having to specify in advance, especially utilizing formats that schools would recognize. One teacher articulated their concerns in this regard:

I think the role of the teacher needs thinking through, as in all composing projects, especially in terms of recording the musical learning that it taking place. Workshops should not become tick box exercises for the national curriculum, but they would not get past the senior management in schools if there was no musical progress demonstrated (project teacher, interview data)

The key phrase here is "would not get past the senior management in schools if there was no musical progress demonstrated'. This is central to the ways schools operate in a performativity-driven results-based culture. Indeed, as Christophersen observes,

Everyone can serve as a source of learning to others, but only teachers are teachers. Teachers are professionals, and teaching in school is teaching within a formal context that has a cultural and societal mandate...(Christophersen $2015,371)$ 
When learning needs to be legislated for in educational settings, then this has to happen. Due to accountability and performativity pressures, the teachers and composers needed to consider what was being learned and therefore what was being evaluated. Swanwick $(1999,84)$ states: "any valid and reliable assessment has to take account of two dimensions: what pupils are doing and what they are learning”. Music learning has to be evidenced in achievement, and understanding comes about from this. This means that learning and doing are intertwined, and these two aspects need to be considered concurrently. Throughout their planning teachers consider the learning that will be taking place, and the progression of knowledge longitudinally over time. However, with artists in schools, the possibility can exist for activity to be mistaken for learning; indeed, planning for activity is often easier than planning for learning. This is not to say that there is not a place for active learning, but it does mean that young people should be engaged in musical learning during such activity. The main issue for work practices involving music is that they involve an interplay between doing - in other words making music - and learning. The teachers understood this, the composers grew to understand it, but began by thinking about doing, and then retrospectively grafting on learning from this.

Although the main area of expertise of the composers was clearly composing, they also brought other related and potentially transferable aspects of their working practices to the project. These included ways in which creativity, especially creative ideas, could be nurtured, fostered, and developed. The composers had considerable expertise in taking original creative musical ideas, working on and with them, and developing them to fruition, something that was often lacking in many of the learners. We know that for many pupils sticking with an idea at the early stages of composing is not something they are used to (Fautley 2014). By focusing on what might be termed 'micro-aspects' of composing, taking small ideas and sticking with them, teachers gained insights into the composing process they could develop with their own pupils As one of the participating teachers observed:

They [learners] are being more creative with their ideas; they are composing music that is more imaginative... they are more confident and resilient with their ideas (project teacher, interview data). 
The professional knowledge of the teachers in terms of defining learning has already been explained, Christophersen $(2013$, p1 ) posits that teachers in such projects often become positioned as “....artists' helpers, students' guards, or as mediators between artists and students" .It is useful, therefore to consider the various types of learning that were taking place during the course of the Resolution project, and the implications of these.

\section{The centrality of learning}

A key issue for music education we have already discussed from the perspectives of the stakeholders in this work are the differences between learning and doing. But we also know from, amongst others, the work of Hattie $(2009 ; 2012)$ that making learning visible is no straightforward process. Professional knowledge, as we have described it, was evidenced, but so was professional learning. After all,

...if learning occurs from and with others, as members of communities, the assumption is that within musician-teacher collaborations, collective knowledge through dialogic practice will be key to transformative practice (Kenny and Christophersen, this volume)

This was the case with this project. Indeed, in order to make sure that there were the necessary facilitating conditions (Torrance 1987) in place for this, the project set aside time for reflection. Schön (1983) has noted that reflection in and on practice are an important part of the professionalism of teachers. Teacher pedagogy often involves careful planning, action and reflection in and on teaching and learning. Within the reflection sessions both teachers and composers had to recognize distinct but overlapping perspectives of composing pedagogy. As the project involved examgroup aged pupils, workshops had to work within examination specifications. This required collaborative reflections between the teachers and composers on teaching and learning where a shared language was fostered. This cultural mediation involved a number of aspects: the composers learning about the school context, the curriculum, exam expectations, performativity, and targeted ways to engage young people. Equally important, the teachers explored composerly thinking and creative processes, and how they could develop these when working solo after the composers had left. 
For the teachers, the composers offered a way in to altered perceptions of practice. Music teachers were exposed to new ways of working, of approaching composing. One teacher noted:

...it produced exciting, innovative performances; pupils grappled with some pretty advanced science, and understood enough of it to translate into music; it was a refreshing and challenging project for all concerned - and those ones tend to be the ones that spark further ideas (project teacher, interview data).

Significantly, the CPD and reflection sessions that were offered for the composers were important for developing an educational perspective of composing in schools, and establishing the scene for what was going to take place. By including time for reflection, composers critiqued, questioned and planned for a continuum of learning. The learning-doing dichotomy was again evidenced here, in that although some of the activities were concerned with doing, such as rehearsing composed pieces, learning was linked to knowledge. Sfard (1998) explores this in her two metaphors for learning; the acquisition and participation metaphors. In the acquisition metaphor the main focus is gaining knowledge, which Sfard observes 'brings to mind the activity of accumulating material goods' (1998:5). Knowledge is developed, meaning is created and this is owned by the individual. On the other hand, the participatory metaphor involves moving from acquisition to participation 'the permanence of having, gives way to the constant flux of doing' (1998:6). The composers and teachers planned for learning by evoking both metaphors; through knowledge acquisition, learning about music, but also participation, learning through making music together.

\section{Discussion}

One of the significant factors that has emerged from this research is the notion of professional knowledge. What we see at play in this project is knowledge existing in three principal domains, those of what might be termed (i) composerly thinking knowledge, which, using Sfard's (1998) terminologies, is, by-and-large, owned and participated in by the composers, (ii) pedagogical content knowledge, which is, again by-and-large, the property of the teachers, and, (iii) lying at the intersection of the 
two, what might be termed as subject domain knowledge. Figure 1 gives a graphical representation of this overlap.

$<<<$ Figure 1 Goes About Here $>>>$

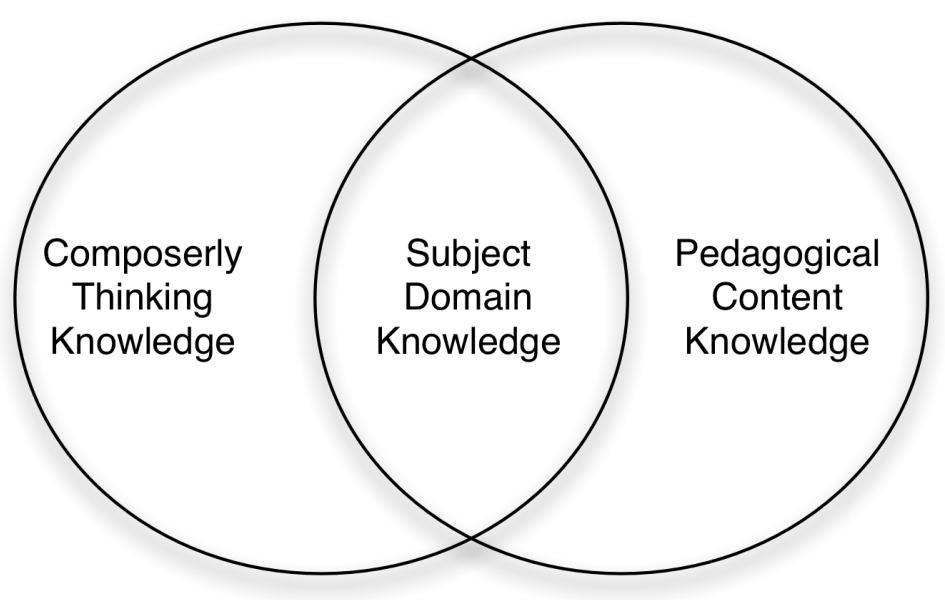

Figure 1: Overlapping domains of professional knowledge

Whilst it may seem the case that these represent relatively finely graded delineations of the three knowledge types, nonetheless in the context of partnership working they are significant. After all, as Bowman observes:

Professional knowledge and expertise are things that are not easily or casually come by. As such, they designate capacities that are not shared by members of society at large; but they also and more particularly designate skills, knowledge, and capacities not shared by individuals in fields of endeavor that might, to the casual observer, seem closely related (Bowman 2007, 114)

It is important too that the Resolution project is not seen as an example of a 'victory narrative' (see chapter 1). The Resolution project was a success, in that it altered thinking, gave young people powerful experiences, and, importantly, produced worthwhile learning, for composers and teachers, but it was because of the recognition of domains of expertise, and the in-built reflection sessions that this took place. We know that in some instances partnership working can be problematic: 
...lack of agreement about the purpose of the partnership, together with a sense of confusion about the roles of the numerous partners, were identified as principal inhibitors to working together (Pinkus 2005, 185)

This project recognized this from the outset, and one of the significant pieces of learning from this work is the notion of actively facilitating, and then building on, reflection time for key stakeholders. These also need integration into funding bids.

The learning of the pupils, whilst important and significant, was not the only learning in this project. Indeed, from the outset this was conceived as a knowledge exchange project for the key stakeholders. Structured reflection, guided by a critical friend, gave this project an impetus which meant that the professional knowledge of all parties was both respected, and enabled. For the hosting organization, BCMG, this meant that there was a developmental relationship with the composers, that meant that their own professional learning was recognized. The teachers learned composing pedagogical techniques that they employ with other classes. In Resolution, reflection sessions were facilitated by researchers. This meant that conversations of the "that was ok" variety were challenged. Reflection needs to be deeper than the "what went well/even better if' variety common in English schools today. Deep reflection is difficult and challenging, and observations that start and end with enjoyment (however important that may be thought) of participants may not be enough. Challenging questions force stakeholders to really think about what they were doing, and why they were doing it. These were not generic pre-scripted questions, but arose from the actuality of the individual sessions. Examples include:

"Why did you accept some ideas but not others from the pupils?" "Why did you intervene in that group at the back?"

"Why did you stop the group working when they seemed to be getting on well?"

"What was the purpose of stopping everyone after a few minutes?"

"Who do you think did the most work this session, the children, the teacher, or the composer?" 
These questions made the participants really think, and using what in psychological research are referred to as "think aloud protocols" (inter alia Sloboda 1985), made the stakeholders share their thoughts in the safe arena of joint reflection session.

Success in this project was not measured by a glittering end-concert, but by learning of participants. As examples, a composer observed:

Working around school music lessons (on a two week timetable) is limiting, I hadn't realized that's how music lessons worked in schools, or that this was why we were working like this, or that how difficult it was to try to get time for this work in school timetables (research interview data).

One of the teachers said:

As the teacher I wanted to be a participating performer and along the way I picked up interesting things about my teaching (research interview data).

Another teacher noted:

I have felt supported and learnt new ideas to bring back into the classroom (research interview data).

These observations may seem superficial, but they are significant in being examples of the ways in which professional learning for teachers about composing and performing, and for composers about school structures took place. This developed the professional learning of each group, and has hopefully had an important function in terms of what they would do next in their respective professional capacities.

\section{Conclusion}

This chapter has described a partnership project focused on composing in schools involving composers and teachers in England. It has unpicked key aspects of professional learning that occurred, and outlined both successes and problems, and drawn out some of this learning for an international audience. We hope that the points 
we have outlined in this chapter are not only of interest to those working in artistteacher partnerships, in whatever jurisdiction they are taking place, but that some of the observations we have made will be helpful for those embarking on such work too. In times of austerity and budget cuts in many jurisdictions, we owe it to our young people to ensure that are having the best exposure to multiple ways of working that we can provide for them. Anything else is a disservice to schools, composers, and music education.

\section{References}

Ball, Stephen. J. 2003. "The teacher's soul and the terrors of performativity." Journal of Education Policy 18 (2):215-228.

Berkley, Rebecca. 2001. "Why is teaching composing so challenging? A survey of classroom observation and teachers' opinions." British Journal of Music Education 18 (2):119-138.

Bowman, Wayne. 2007. "Who is the "We"? Rethinking professionalism in music education." Action, criticism, and theory for music education 6 (4):109-131.

Christophersen, Catharina. (2013). "Helper, guard or mediator? Teachers' space for action in The Cultural Rucksack, a Norwegian national program for arts and culture in school. International Journal of Education \& The Arts 14

Christophersen, Catharina. 2015. "Changes and challenges in music education: reflections on a Norwegian arts-in-educatiion ptogramme." Music Education Research 17 (4):365-380.

Eraut, Michael. 1994. Developing professional knowledge and competence. London: RoutledgeFalmer.

Fautley, Martin. 2014. Listen, Imagine, Compose - Research Report. London: Sound and Music.

Fautley, Martin, Richard Hatcher, and Elaine Millard. 2011. Remaking the curriculum: re-engaging young people in secondary school. Stoke-on-Trent: Trentham.

Hattie, John. 2009. Visible learning: A synthesis of over 800 meta-analyses related to achievement. New York: Routledge.

Hattie, John. 2012. Visible Learning for Teachers - Maximizing impact on learning. Abingdon: Routledge.

Kenny, Ailbhe. 2010. "Too cool for school? Musicians as partners in education." Irish Educational Studies 29 (2):153-166.

Kenny, Ailbhe. 2014. "Sound connections for institutional practice: cultivating 'collaborative creativity' through group composition." In Developing 
Creativities in Higher Music Education: International perspectives and practices, edited by P Burnard, 469-493. Abingdon: Routledge.

Kenny, Ailbhe. 2016. Communities of Musical Practice. Abingdon: Routledge.

Lave, Jean, and Etienne Wenger. 1991. Situated learning: Legitimate peripheral participation. Cambridge: Cambridge University Press.

Nardi, Bonnie. 1996. "Studying context: A comparison of activity theory, situated action models, and distributed cognition." In Context and consciousness: Activity theory and human-computer interaction, edited by B. Nardi, 69-102. Harvard: MIT Press.

Pinkus, Susanna. 2005. "Bridging the gap between policy and practice: adopting a strategic vision for partnership working in special education." British Journal of Special Education 32 (4):184-187.

Ruffer, David. (1988) "The London Sinfonietta Education Programme - An analysis of an interface between the professional artist and music in education." British Journal of Music Education, 5, 1: 45-54.

Salomon, Gavriel, ed. 1993. Distributed Cognitions. Cambridge: Cambridge University Press.

Sawyer, R Keith. 2003a. Group Creativity. Music, Theater, Collaboration. Mahwah, New Jersey: Lawrence Erlbaum.

Sawyer, R Keith. 2003b. "Emergence in Creativity and Development." In.

Shulman, Lee. 1986. "Those who understand: knowledge growth in teaching." Educational Researcher 15 (2):4-14.

Sloboda, John. 1985. The Musical Mind. Oxford: Oxford University Press.

Swanwick, Keith. (1994) Musical Knowledge - Intuition, Analysis and Music Education, London, Routledge.

Torrance, E Paul. 1987. "Teaching for creativity." In Frontiers of creativity research: Beyond the basics, edited by S.G. Isaksen, 189-215. Buffalo, NY: Bearly Limited.

Wenger, Etienne. 1998. Communities of practice: learning, meaning, and identity. Cambridge: Cambridge University Press. 